With these facts before us, it behoves us to act with great caution where pregnancy is present; for there can be no doubt that now and then we meet with physiological and pathological effects, which are quite beyond the common beaten track of observation, and which can only be duly appreciated when the fact that pregnancy exists is itself known.

It has been urged by some professional men, that while these peculiar symptoms incident to pregnancy are possible, they are not common. I admit the fact; and I admit it on twenty years of active experience. But it strikes me, from the same experience, that cases of irritant poisoning are much less common; and I have sufficient confidence in my countrymen and women to believe that this view is correct. Any way, I am very happy that, in my cases, I brought no one up to trial for a life; and I submit that medicine will soon be called Moloch, if many similar cases, because they resist remedies, are to be set up as illustrations of slow poisoning by felonious administration.

[To le continued.]

\section{ON THE TREATMENT OF ASTHMA BY SEDATIVES.}

By HYDE SALTER, M.D., F.R.S., Fellow of the Royal College of Physicians, and Assistant-Physician to Charing Cross Hospital.

Tobacco: Stramoniule : Chroroform : Opium : Loberia : INDIAN HEMP : ATHER.

THE recognition of the nervous nature of asthma, of the paroxysmal character of its symptoms; of the fact that the air passages were in a state of spasm; that a part at least of its essential pathology apneared to be a morbid susceptibility to certain stimuli ; that many of its exciting causes were such as exalted nervous irritability ; that the suljects of it were commonly individuals of quick and mobile nervous systems; these, and analogous considerations, long ago suggested the use of sedatives both for the prevention and alleviation of the asthmatic paroxysm.

The modus operandi of sedatives, both in the cure and pre vention of asthma, is doubtless by allaying nervous irritability destroying for the time that morbid sensitiveness of the pul monary nerrous system that constitutes so essential a part of the disease. And whilst, on the one hand, it is the nervous theory of asthma that has suggested the use of sedatives, their efficacy on the other-the immediate and perfect relief that follows the use of some of them--is among the best proofs we have of the correctness of this nervous interpretation of the phenomena of the disease.

Of all the classes of remedies used in asthma, I think that sedatives constitute the most numerous. I wish I could say that they excelled others in efficacy as much as they do in numbers. But they are of very unequal power; for while one or two of them are of very great value, others appear to be of little worth, and some even prejudtciat. Chtorororm, for example, is, in my opinion, one of the most valuable remedies for asthma that we possess; the inhalation of its vapour putting a stop to the asthmatic paroxysm more speedily and more certainly than anything else I know. Opium, on the other hand, I have found, as far as my experience has gone, positively worthless.

Moreover, with regard to sedatives, asthma exhibits very strongly its characteristic caprice;-stramonium smoking is, to some patients, an infallible cure, while others might just as well smoke so much sawdust, and not only receive no benefit, but experience no result of any kind from it.

The principal remedies of this class are :-

I. Tobacco, in sedative doses; II. Chloroform ; III. Opium ; Iv. Stramonium ; v. Lobelia ; vI. Indian Hemp; vir. Ether, in sedutive doses.

Of some of these I have had very little practical experience. $I$ will speak of those of which I have, and first of -

I. ToBAcco. I have, in a previous paper, spoken of tobacco as a depressant. But tobacco as a sedative is quite another thing. 'The dose is different; the physiological effects are different; the principle of the cure is entirely different. In smoking with the view of producing depression, the individual must be unaccustomed to the drug, or the tobacco very strong, or the dose very large; in smoking for sedation none of these is necessary. For tobacco to cure asthma as a depressant it must produce collapse; as a sedative it merely produces that composing and comforting condition with which smokers are so familiar. As a depressant it renders spasm impossible by knocking down nervous power (doubtless by poisoning the nervous centres) ; as a sedative, by temporarily effacing a morbid sensitiveness to certain stimuli, and inducing a normal in. difference and tolerance of them. Any one may experience the sedative effects of tobacco, and all smokers do habitually; but the production of its full depressant action is almost impossible in those who have long accustomed themselves to its use; in others, however, as in women and children, it is so easy, that the difficulty is to prevent sedation from running into depression. It is for this reason that it is necessary, in administering tobacco as a sedative only, to the uninitiated, the delicate, or the young, to give the very mildest form, in carefully measured quantities, and to insist on its slow and deliberate exhibition.

It is of the sedative use alone of tobacco that $I$ am now speaking.

Asthmatics are very commonly smokers, and many of them find in the habit an almost unfailing antidote to their disease. But in almost all the cases that I have met with, it is rather as a prophylactic that it is used-to secure immunity when under dangerous circumstances, or to meet the first threatenings of an attack - than as a veritable curative to cut short spasm.

Ir. Chloroform. One of the most powerful and speediest remedies which we possess for asthma, to which I should, perhaps, give the first place of all, is chloroform. It is, of course, a comparatively recent remedy; but its marked physiologica effects early suggested its appropriateness, and the result has fully justified the trial. I have not had many opportunities of witnessing its effects personally, because when asthmatic patients consult one they are generally not suffering from the disease at the time; but in the cases in which I have witnessed it I have been very much struck with the completeness of the control which it exercises over the asthmatic condition, and with the absence of all danger in its administration, provided the asthma is of the uncomplicated spasmodic form. If the only source of dyspnœa is bronchial spasm, it seems to me that it may be as safely given to an asthmatic in the height of a paroxysm as to a healthy person.

I shall not easily forget the first case in which I administered it. A poor woman was brought into King's College Hospital at the time that I was house physician there, supposed to be dying by those who brought her in. She was quite unable to move, and could barely speak; but it was easy to perceive, from the violent action of the respiratory muscles and the loud wheezing that accompanied it, that the suffocation from which she was suffering was of the asthmatic kind. I at once administered chloroform. After a few whiffs the spasm began to yield, and before I had given her enough to make her insensible it had quite subsided and her breathing was free. In ten minutes after entering it she left the hospital-well.

Even in asthma with bronchitis I have known it, if carefully administered, of great service, by getting rid of the asthmatic element of the dyspnwa, and so putting a stop to one of the sources of suffering, and one of the causes of pulmonary congestion and bronchial exudation; and at the same time, by relaxing the constricted air passages, facilitating the discharge of the accu mulated mucus. In chronic bronchitis I have seen at leas half of the dyspnœa vanish on its administration, showing how much of the symptoms were due to spasm. I think its useful ness in these cases has been overlooked, $\approx n d$ that, if carefully and tentatively given, it might be tried in them without risk. Certainly for the time the patient is placed under much better circumstances, even as far as the bronchitis goes.

The sooner it is given after the commencement of an attack the better, for if the spasm has existed for some time it is ap to recur as soon as the influence of the chloroform passes off The plan recommended by Dr. Russell Reynolds, of recurring to it at the first indications of an attack is, I think, a very good one, for the spasm yields with much greater facility, and is cut short while it is in so incipient a state that the treatment is virtually preventive. $\mathrm{He}$ mentions the case of a young lady (Lancet, October 29th, 1853) who, by inhaling a few drops on her handkerchief whenever an at tack threatened, at once averted it, and was thus virtually cured of her troublesome complaint.

Dr. Walshe says he has seen three results of chloroform inhalation, administered during a fit of asthma, and pushed to narcotism;-" Total relaxation of the spasm during the continuance of insensibility, with the immediate return of dyspnœ on the restoration of consciousness; gradual return of the difficult breathing as consciousness is restored; and suspension, or at least mitigation, of the paroxysm for the time being." The last effect he has found the rarest of the three; but, on 
the other hand, the temporary relief afforded by chloroform is sometimes more complete and more rapid than that afforded by any other agent.

As in all other cases, so in asthma, the patient should never administer the chloroform himself. Dr. Todd's remarks on this point are so judicious, and enforced by so striking an example, that I cannot forbear quoting them. "In the administration of chloroform," he says, "I would give you this twofold caution :First, to give it gradually and cautiously, and not in a full dose, not to produce insensibility, especially if there be anything like blueness of the surface; because, though remedial to asthma it will tend to increase the very consequences which are most to be feared from the circulation of venous blood. Secondly, to impress on your patient that he must never give it to himself, nor without the presence of a medical man. 'Ihe following case was related in the papers the other day: $-\Lambda$ person who was in the habit of curing his attacks of asthma by inhaling chloroform, when administering it to himself one day, and when in a state of half subjection to its influence, in order to produce the full effect placed his handkerchief on the table and buried his mouth in it; his insensibility became deeper and deeper, till at last he was too far gone to raise his head. He therefore continued inspiring it; his coma became more and more profound; and, a short time after, he was found in that position quite dead." (1Iedical Gazette, Dec. 1850.)

III. Orivar. To opium in asthma I have myself a great objection. I do not mean to impugn the correctness of those who profess to have seen benefit derived from it; all I would say is, that I am not certain I have ever seen it do good; that I have often seen it do harm; and that I should have antecedently expected, from its known physiological action, that it would be prejudicial, and tend to increase the very condition for which it is given. I have endeavoured to show that sleep favours asthma; and that it does so on account of the ascendancy that excito-motory action then acquires. The heavier and more oppressed the patient is the intenser does the asthmatic spasm become; and, on the other hand, the wider awake and more vigilant he is-the more exalted sense and will-the more readily does it yield, so that often simple rousing is enough to stop an attack that was gradually creeping on the sleeper.

Anything, therefore, that soporises aggravates the asthmatic tendency. Now this is exactly what opium does. What we want in asthma is a sedative that, like stramonium, sedates but does not narcotise ; or one that, like chloroform, goes much further, and produces universal muscular relaxation. And not only does opium act prejudicially by tending to exalt reflex action in proportion to the drowsiness and lethargy it produces, but, by lowering sensibility, it prevents that acute and prompt perception of respiratory arrears which is the normal stimulus to those extraordinary breathing efforts which are necessary to restore the balance.

But, beyond this, opium seems to have a specific tendency to excite involuntary muscular action, and induce a tendency to spasm. The exact explanation of this will depend upon the theory of muscular eontraction that is adopted; and into this at present disputed physiologioal question, I will not enter. If, then, I had been asked, antecedently to all experience, whether opium would be useful in asthma, I should have replied, on the strength of the spasm-theory of the disease, that it would not.

But I would not let any theoretical objection run counter to clinical evidence; and if experience said "give opium", no theory should prevent my recommending it. My own experience, however, coincides with these objections; and I am disposed to think that the frequency with which it is given in asthma depends upon an unthinking following of routine and a want of close and exact observation. Not only have I often seen asthma worse for it when given during the fit, but I have seen it brought on when it did not previously exist. An asth. matic gentleman, in whom I have often watched this, and who is frequently obliged to resort to opium on account of colic, never takes it without being rendered more or less asthmatic by it, however free from the disease he may have previously been.

I would say, then, prefer any other sedative to opium; and, unless there is some special complication that indicates it, never give it at all.

IV. STnasionilyr. The smoking of the datura as a remedy for asthma was introduced in 1802 , from India, by General Gent, and soon obtained, as new remedies are apt to, the reputation of being specific and infallible-every body with any shortness of breathing was smoking stramonium. Its use, however, has illustrated the general inapplicability of any one remedy to all cases of a disease, and the special caprice of asthma; and time has shaken it into its proper place, and assigned it its true worth; - that its original reputation greatly exaggerated its merits, but that it has undoubted though very unequal value, and will probably always maintain its place amongst the real remedies of asthma.

Perhaps no drug has been given with more contradictory results, and perhaps in no way is the caprice of asthma better illustrated than in its effects in different cases. In some it is the remedy; in the majority of cases, as ordinarily used, it seems utterly inoperative, and in some positively injurious.

"Sometimes," writes Dr. Watson, "it calms the paroxysm like a charm. The late Dr. Babington told me of a patient of his, who had been grievously harassed by asthma for a series of years, but who declared to him, after he had made a fair trial of stramonium, that he no longer ' cared a fig' for his asthma, which he could always stop in a moment. So a Mr. Sills, in a collection of communications relative to the datura stramonium, published in London in 1811, states that he had been a great sufferer from asthma; that the fits continued, with short interruptions, from thirty-six hours to thre $\mathbf{e}$ days and nights successively, during which time he had often, in the seeming agonies of death, given himself over, and even wished for that termination to his miseries. But, having at length discovered the virtues of stramonium, he uses this strong language. 'In truth, the asthma is destroyed. I never experience any ill effects whatever from the use of the remedy; and I would rather be without life than without stramonium.'

Among several striking cases of the efficacy of stramonium, communicated by Dr. Gooch of Croydon, I will quote the following:- "Mr. L., 22 years old, for the last four years has had great difficulty in breathing, attended by wheezing and cough, which attack him suddenly, when in bed or at meals, disabling him from his business, and sometimes continuing more than a week. It occasionally seizes him so violently that he is unable to speak, and appears to be threatened with instant suffocation. He has had much medical advice, without receiving material benefit. He now smoked the thorn-apple, swallowing the saliva and smoke; by these means the fit terminates in a few minutes. He smokes every day, even when the fit does not occur. Sometimes it attacks him while dining in company; in whicb case he retires, smokes a pipeful, and returns to his friends brenthing freely." I might go on quoting cases ad libitum, but must content myself with referring the reader to many very interesting and striking ones in the seventh and eighth volumes of the Edinburgh Medical and Surgical Journal, the twenty-sixth volume of the Medical and Plysical Journal, and the various medical journals published at the early part of the present century.

In most of the cases that I have personally witnessed, it has given only temporary relief-mitigated rather than cured the spasm; but, in a case recently communicated to me, its effects appear to be nearly as striking as in the cases I have just quoted. The patient was what is commonly termed a " martyr to gout", and suffered most severely from asthma. He could not walk, in consequence of the gouty state of his legs and feet; and one of his amusements was to pick the chalk out of his fingers with a knife! "I remember," continues my informant, "one day, when I was at his house, he came home in his little hand-carriage, in which it was his wont to be wheeled about, and, on being helped into the parlour, he was in such a state from a violent attack of his asthma that he could not speak, but made signs to his daughter, by pointing to a cupboard, that she should reach him his pipe of stramonium. She lighted it, and, after he had taken a few whiffs, the breath ing became relieved, and he was able to speak; and, after a few more, the spasm and oppression so completely vanished that he could converse as well as usual."

On the other hand, one is always being disappointed with it in a large percentage of cases it does no good at all, and in some has been said to prove injurious, and in a few instances fatal. Dr. Bree tried it in eighty-two cases; in fifty-eight of these it had no permanent effect, and in the remaining twentyfour it acted injuriously. General Gent, who was instrumental in introducing the practice, fell a victim to it. Aggravation of the dyspnœa, paralytic tremblings, epilepsy, headache, and apoplexy, are some of the evils said to have been induced in some of the cases above referred to.

To what are these contradictory results to be attributed? Partly, doubtless, to the caprice of the disease, which behaves in the most irregular way to all remedies; but partly, I think, to the mode of preparation and drying of the drug. An asth. matic patient of mine informed me that while he received great 
benefit from stramonium grown and dried by a relative of his, that which he gets at the shops does him no good whatever. He sent me a specimen of this home-prepared stramonium, and certainly it was a very different thing, both in appearance and smell, from what one commonly sees: it had not lost its fresh greenness, nor the genuine solanaceous smell. I think, therefore, asthmatics would do wisely to grow and prepare their own stramonium. Part, too, may depend on the time at which it is administered; stramonium, like other remedies, will cut short an incipient spasm, while over one that has been long established it has but little power. The great thing is to give it in time; and for that purpose, since the patient in general is awoke from his sleep by the paroxysm, he should put his pipe, already filled, with the means of lighting it, by his bedside over night, so that on awaking with the dyspnœa he might imme. diately use it.

My friend Dr. Bullar of Southampton tells me that he has seen benefit from the inhaling (not the mere smoking) of stramonium smoke. "A year ago," he writes, "I met with an old asthmatic, who had cured himself and relieved many others by using cold stramonium-smoke. He smoked the stramonium as you do tobacco, then puffed the smoke into a tumbler, and then inhaled the cold smoke into his lungs. I am now attending an asthmatic lady, who could not inhale the hot smoke, but who inhales the cold smoke in this way with great relief.'

The same plan of inhaling, I find mentioned in a very in teresting case in the Edinburgh Medical and Surgical Journal, as far back as 1811 . The patient says :- "The way in which I employ this remedy is thus: I fill a common tobacco-pipe with the stramonium cut in small pieces, and inhale the smoke as much as possible into the lungs, which causes heat and pain about the fauces and throat, and I am obliged to breathe once or twice before I can inhale it again, when I draw in the smoke; and so on alternately till the herb is consumed, which occupies about half an hour, once a day. The saliva I swallow." Now this is introducing the drug in a different, and certainly more powerful, way than by simply smoking it, and one well worth trying. By ordinary smoking absorption takes place by the oral surface only; here it is introduced into the lungs them. selves and absorbed by the respiratory surface, whose absorben powers exceed those probably of any other surface of the body. Besides, it has the advantage of being applied to the very part affected.

There are several species of datura in use, of which that commonly employed in this country, the datura stramonium appears to be the least powerful. The datura ferox, which was first introduced by General Gent, seems to be much stronger. The datura tatula, from which what are called stramonium cigars are made, appears also to be stronger.

The seeds are much more powerful than the other parts of the plant; their analysis yields more than three times as much of the active principle, daturia. My friend Dr. Alexander of St. Helena, where spasmodic asthma appears to be rather common, informs me that, while he has found the smoking of the leaves almost worthless, he finds the smoking of the seeds a most efficient'and powerful remedy; and that whereas he was disposed before he tried the seeds to regard the reputation of stramonium as a myth, he has since their employment come to the conclusion that it is one of the most satisfactory of the remedies of asthma. He states, however, that the effects of the seeds are so powerful, that great care is necessary in their administration; they should be smoked in very small and gradually increasing quantities, and their effects closely watched. $\mathrm{He}$ has seen, on two or three occasions, alarming symptoms supervene on their use. I have not yet tried the remedy of smoking the seeds, but I shall certainly do so. I do not see why the leaves should not be steeped in a decoction of the seeds, dried, and then smoked, so as to administer by smoking reliable preparation of an uniform strength.

Exhibition by smoking certainly appears to have some ad vantages; absorption by the oral surface, especially if combined with inhalation, is sufficiently rapid, and at the same time gradual and more regulable than by the stomach. One would rather either take or give any preparation of the solanacea by smoking than by swallowing. One feels, with regard to such ticklish remedies, the full force of the facilis descensus and its alternative. Nevertheless, I frequently give the extract, and often with marked benefit. It should be commenced, I think, in quarter-grain doses, gradually increased to a grain or a grain and a half. The Edinburgh preparation - an alcoholic, and not a watery extract-is the best and most reliable, the active principle, daturia, being very soluble in alcohol, but very sparingly so in water. The tincture may also be given in from ten-minim to twenty-minim doses every four hours, gradually increased till it occasions some obvious effect on the system.

I may say, in conclusion, with regard to this drug, that its great value in some cases would, in spite of its too frequent impotence, always induce me to give it a trial in cases in which it had not been tried; that I do not believe it is attended with any danger except from the most egregious over-dosing; that, since the common fault is want of power, I should prefer the stronger forms, the ferox and tatula, giving them tentatively and carefully; that inhalation of the smoke and swallowing the saliva may be advantageously combined with the ordinary method of smoking; and that it cannot be given too early in an attack. I think it does more in the way of prevention than cure; I think I have seen better results from the long continued practice of smoking a pipe of it the last thing at night, whether an attack of it is threatening or not, than by waiting until a paroxysm comes on. I have seen this nightly pipe, the last thing before going to bed, apparently keep the disease at bay for an indefinite time, as long as it was continued, but followed by its immediate reappearance as soon as it was left off. The stramonium seems to leave for some hours a state of nervous system in which the asthma is not likely to come on; and, since its invasion is almost always at night, a pipe at bedtime conducts and guards the patient through the critical time. I should say, then, let this always be one part of its administration; and keep up the practice of smoking it the last thing at night for some months after the disease appears to have yielded, so as to completely break through the habit.

v. Lobelia. Of lobelia I can say but very little; and the reason I can say so little is, that, being doubtful of its really doing any good, I have for some time ceased to prescribe it. But I have lately heard of some successful cases of its employment by medical friends; and I am inclined to think that my want of success, and the want of success that has generally attended its use in this country, has depended upon not giving it in sufficiently large doses. I have never given it in larger doses than from fifteen minims to half a drachm; but I find that in America, where it is much more used than in this country, and has a high reputation as an almost unfailing specific in spasmodic asthma, they give it in vastly larger doses they consider half an ounce a full dose, but recommend two drachms every two or three hours till some decided effect is manifested. In many successful cases on record it has been given in small antispasmodic doses ;* but I am inclined to think its great success among the Americans, and in Dr. Elliotson's hands, and in many cases which I find scattered about in the journals, depends upon its having been given in doses producing the characteristic depressant action of the drug. In fact, the condition that a large dose produces is such as I should think no asthma could resist; it is almost identical with tobacco-poisoning - giddiness, faintness, sickness, cold sweat, and complete muscular relaxation. I should have the most perfect faith in its value in asthma when producing such symptoms as these; but they are not the symptoms one likes to produce in one's patients, and cannot be considered devoid of danger. I see no objection, however, to Dr. Elliotson's plan of giving frequent small and gradually increased doses. $\mathrm{He}$ recommends ten minims every quarter or half hour, increasing each dose a minim till the disease yields, or it seems to disagree with the patient. If this last should be the case, and vomiting and headache come on, the medicine must be left off for a time, and continued when the headache, etc., is removed, not increasing the dose beyond the last given.

One circumstance that makes it the more necessary to be careful of overdosing a patient, and that strongly inculcates commencement with small doses, is that different individuals tolerate it in such different quantities. Dr. Elliotson states that in some instances a single minim will produce sickness, while in other cases, on the contrary, sixty or even ninety drops were taken for a dose. He mentions a young lady who, being subject to spasmodic asthma, always carried ninety drops of the tincture in a small phial; this dose she swallowed when. ever an attack of the disease came on. He mentions, also, the following extraordinary and almost incredible case:- "A me. dical man, suffering from asthma, having failed to obtain his usual relief from his usual dose of the tincture, increased it to fifty-minim doses, which he took every hour for twenty-four

* "I have, for upwards of two years past, been afflicted with inveterate asthma, which deprived me of natural rest, and the spasmodic effects of which were frequent and most distressing. When $I$ found these paroxysm coming on, I took fifteen drops of tincture of lobelia, which invariably gave me immediate relief, although previously to my using this remedy the violent fits often lasted for hours." (London Mledical Gazette, vol. iii.) 
hours. Experiencing but little relief he added a minim to each dose till it reached seventy-five minims; this he took for forty-eight hours, and the disease was relieved. His pulse was becoming intermittent, perspiration broke out over the body, and he became languid; small doses of ammonia soon restored him to his usual state. In the last four days this man must have taken twelve ounces of the tincture." (Lancet, vol. ii, p. 144.)

Another circumstance that makes it the more necessary to be careful not to administer this drug in undue quantities is, that different specimens of it differ so much in strength. Dr. Elliotson complains of this, and assigns it to faulty preparation. But the Americans say that the plant itself varies very much in strength, depending chiefly upon the situation in which it has grown; that which has grown in damp situations being rank and strong, while that which has grown in dry places is almost inert. But I must not say any more on a medicine about which $I$ began by saying I could say nothing.

vi. IndAan Henp. The Indian hemp, cannabis sativa, is much given in India as an anti-asthmatic, and among the natives has a great reputation. I can easily imagine from its physiological action that its reputation is well deserved. It is at once a stimulant and a sedative. I should be inclined to think it would act best in small stimulant doses. Given in this way it produces the same effects as coffee, only in a more marked degree-it exhilarates, imparts great activity and intensity to the intellectual faculties, and exalts the functions of animal life. In any case in which coffee is useful, I should expect that Indian hemp would be so in a greater degree. I think in large doses it might even do harm, from its hypnotic tendency. In this respect, there is the same objection to it as to opium. I can say nothing of it from my own personal expe. rience; I have never given it, nor seen a case of asthma in which it has been given.

vir. AEther. Ather is mentioned as a remedy by almost all writers on asthma. I have never seen but one case in which it did any good, though I have given it in scores of cases. In that case it acted, and always had acted, like a charm. I cannot say that in any other case I ever saw it do a particle of good, and think I have often seen it produce a disagreeable oppression, and even increase the spasm. Others speak well of it; but that is the result of my experience.

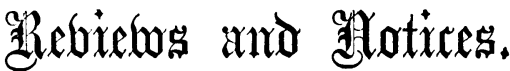

On Wounds and Injuries of the Eye. By White Cooper, F.R.C.S., Oculist to the Queen; Ophthalmic Surgeon to St. Mary's Hospital ; etc. London: Churchill. 1859.

THE author, when in charge of difficult and anxious cases, had often felt the want of an English work specially devoted to this subject. In the present volume, he has attempted to supply this hiatus in ophthalmology, by presenting to the profession ten chapters which are replete with important clinical information derived from his own practice and that of his confrères who are or have been engaged in the cultivation of the same branch of surgery. The work is illustrated by numerous cases, spirited woodcuts, and some coloured drawings. The latter evince a marked advance, as works of art, upon anything of the kind which has yet been published in the text-books of this country.

In respect to the treatment of inflammation, which engages so large a share of the attention of ophthalmic surgeons, $\mathrm{Mr}$. Cooper appears to be eclectic, avoiding, on the one hand, the cxcesses in depletion and mercurialisation which characterise the therapeuticism of the followers of the Beer school, and, on the other, the premature and almost universal administration of tonics which marks the practice of what may be termed the modern Brunonians.

As an instance of the author's treatment, we adduce the following case :-A pallid sickly-looking shoemaker applied to Mr. Cooper on July 2. Six weeks previously, a particle of iron from a blacksmith's anvil had become imbedded in the cornea of the right eye, where it remained. The palpebræ were much swollen and congested; the conjunctiva, sclerotica, and cornea, were acutely inflamed. The foreign body lay imbedded in the cornea, surrounded by infiltrated pus; and the anterior chamber was half-filled with pus. Intense pain in the eye and head deprived the patient of sleep, and of the ability to labour. There were great debility, a weak pulse, and foul tongue. Mr. Cooper extracted the foreign body, ordered two leeches to the. neighbourhood of the eye, a warm poultice, and frequent fomentations; three grains of calomel immediately ; an aperient draught after the expiration of six hours; six grains of Dover's powder every night. The patient was not seen again till July 9th. The pus had then entirely disappeared from the cornea; the iris and pupil had become distinctly visible; there was asthenic congestion of the sclerotica. He was ordered powder of cinchona and bicarbonate of soda, five grains of each, to be. taken three times a day, with nutritious diet; the bowels to be regulated by sulphate of soda. A blister was applied behind the ear. In six days afterwards, merely a slight film marked the seat of injury to the cornea; the eye was well.

In illustration of the importance of a full and complete examination before deciding against the presence of a foreign body, the author relates the case of a tradesman who, while waiking in the street, felt something strike into his right eye, with acute pain. He consulted two surgeons, who bled and salivated him. Five weeks after the accident, much debilitated, still in pain, and with gums so sore that he could not eat, the patient applied to the North London Eye Infirmary, where, for the first time since the accident, the upper lid was everted, and a fragment of cinder, of the size of a pin's head, found firmly adherent to its conjunctiva. A rapid recovery followed its removal.

When a foreign body is impacted in the upper cul.de-sac of the conjunctiva, the symptoms are those of chronic inflammation. The conjunctivæ or palpebræ become thickened, and the papillæ hypertrophied, sometimes to an enormous extent; the conjunctiva oculi participates in the thickering; and a thick yellow discharge agglutinates the lashes, accumulates at the canthi, and thus renders the eye an object of disgust. When this is seen, especially when there is the appearance of fulness about the upper lid some time after a foreign body has entered the eye, a full examination should be insisted on. The subsidence of pain often misleads. The patient feels sure that the body has "worked out", and dislikes the idea of the lid being everted; but that is the proper course to adopt. If, on turning the lid, a fungous-looking mass is exposed, the particle will most probably be found impacted in its centre; if hidden in the fold of reflection, the hypertrophy of the papillæ will be strong evidence of its presence.

In the second chapter, the author treats of Foreign Bodies in the Eyeball. The gravity of the injury will vary with the size and situation of the foreign body. It is singular how tolerant some eyes are of substances which enter the anterior chamber; indeed, the number of recorded instances is great in which bodies have there remained, and become encysted, without material injury to the eye. A chip of metal may be driven with such force and velocity as to pass through the cornea, the wound closing behind it so instantaneously as to retain the aqueous humour. The wound made by a penetrating fragment of percussion-cap is a clean incised one, and the vision is not destroyed immediately in those cases in which the cap has gone through the sclerotica, and has not injured the transparent parts of the eye. The lodgment of a foreign body in the crystalline lens is rare. Mr. Cooper gives four cases, three of which occurred in the practice of continental surgeons. The danger of leaving a foreign body in such a position is forcibly illustrated by a case which occurred in the practice of Dr. Jacob. A piece of copper cap remained on the lens of a little boy for two or three years, without exciting irritation. The lens became absorbed, the foreign body remaining entangled in the opaque capsule. In a year afterwards, the chambers were 